\title{
Challenges in Total Hip Replacement after McMurray's Osteotomy: A Report of 3 Cases and Review of Literature
}

\author{
Raju Vaishya, FRCS Eng, Abhishek Vaish, MCh, Aabid Husain Ansari, MBBS \\ Department of Orthopaedics and Joint Replacement Surgery, Indraprastha Apollo Hospitals, New Delhi, India
}

Background: McMurray's osteotomy of the hip was a popular surgery practiced for almost 5 decades for the management of the fractured neck of the femur and hip osteoarthritis since its first description in 1936. It is an oblique, medial displacement intertrochanteric osteotomy. In the long term, McMurray's osteotomy patients develop limb length discrepancy and secondary osteoarthritis due to the altered biomechanics of the hip and may require total hip replacement (THR). THR after the previous osteotomy is more challenging than that for unoperated hip joints due to severe distortion of the hip anatomy and soft-tissue contractures. These challenges are related to distorted bony anatomy, soft-tissue contractures, and the choice of implants.

Methods: Three patients with previous McMurray's osteotomy of the hip developed secondary osteoarthritis and underwent total hip replacement. We discussed specific challenges encountered during THR and techniques to deal with such problems.

Results: All patients had pain-free hip, with minimal residual shortening (average, $1.2 \mathrm{~cm}$ ) at an average follow-up of 3.67 years (range, 1 to 6 years). The Harris hip score improved significantly postoperatively and no complications were encountered.

Conclusions: A detailed and careful preoperative planning, correct execution of surgical techniques, and postoperative rehabilitation are the keys to the successful management of these cases.

Keywords: Hip, Osteoarthritis, Osteotomy, Total hip replacement, Femoral neck fractures

Until approximately 4 decades ago, when the options of arthroplasty and adequate means of fracture fixation were not available, various hip osteotomies were used as salvage operations for the treatment of fractured neck of the femur. Amongst all the osteotomies of the hip, McMurray's osteotomy was one of the most popular procedures. It was first described by Mr. T.P. McMurray of Liverpool, England, in $1936 .{ }^{1)}$ McMurray's osteotomy is anoblique, medial displacement intertrochanteric osteotomy. It was used widely for the treatment of femoral neck fractures (fresh fractures, delayed union, and nonunion), and degenerative

Received March 17, 2020; Accepted June 26, 2020

Correspondence to: Raju Vaishya, FRCS Eng

Department of Orthopaedics and Joint Replacement Surgery, Indraprastha

Apollo Hospitals, Sarita Vihar, New Delhi 110076, India

Tel: +91-9810123331, Fax: +91-11-26823692

E-mail: raju.vaishya@gmail.com hip arthritis. ${ }^{2)}$

In the long term, McMurray's osteotomy patients develop limb length discrepancy and secondary osteoarthritis due to the altered biomechanics of the hip and may require total hip replacement (THR). THR after the previous osteotomy is more challenging than that for nonoperated hip joints due to severe distortion of the hip anatomy and soft-tissue contractures. ${ }^{3)}$ We present our experience of 3 cases of THR after McMurray's osteotomy and discuss the tips and tricks for dealing with surgical difficulties in these cases.

\section{METHODS}

We managed 3 adult males, who underwent THR after McMurray's Osteotomy for fractured neck of the femur (Table 1). All these patients presented with secondary osteoarthritis. These males aged between 59 and 68 years 
Vaishya et al. Total Hip Replacement after McMurray's Osteotomy

Clinics in Orthopedic Surgery • Vol. 12, No. 4, $2020 \bullet$ www.ecios.org

Table 1. Demographic Details of Total Hip Replacement (THR) Cases

\begin{tabular}{|c|c|c|c|c|c|c|c|}
\hline $\begin{array}{l}\text { Case } \\
\text { No. }\end{array}$ & $\begin{array}{l}\text { Age } \\
(y r)\end{array}$ & $\begin{array}{c}\text { Indication for } \\
\text { McMurray's Osteotomy }\end{array}$ & Indication for THR & $\begin{array}{l}\text { Preoperative } \\
\text { Harris hip score }\end{array}$ & $\begin{array}{l}\text { Postoperative } \\
\text { Harris hip sore }\end{array}$ & $\begin{array}{l}\text { Follow-up } \\
\text { period (yr) }\end{array}$ & Type of THR used \\
\hline 1 & 68 & Femoral neck fracture & Secondary osteoarthritis & 59 & 80 & 06 & $\begin{array}{l}\text { Uncemented (Trident cup, } \\
\text { Accolade stem, Stryker) }\end{array}$ \\
\hline 2 & 59 & Femoral neck fracture & Secondary osteoarthritis & 65 & 87 & 01 & $\begin{array}{l}\text { Uncemented (Trident cup, } \\
\text { Accolade stem, Stryker) }\end{array}$ \\
\hline 3 & 66 & Femoral neck fracture & Secondary osteoarthritis & 61 & 85 & 04 & $\begin{array}{l}\text { Cemented (cemented cup, } \\
\text { Exeter stem, Stryker) }\end{array}$ \\
\hline
\end{tabular}
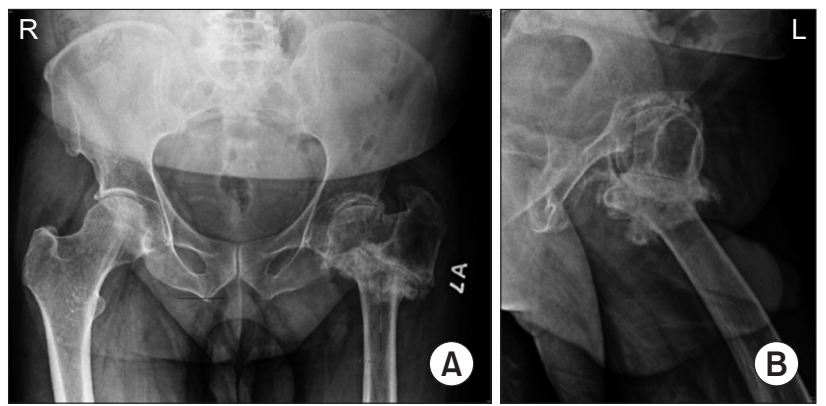

Fig. 1. Plain radiographs: anteroposterior $(A)$ and lateral $(B)$ views of the hip showing ununited intertrochanteric osteotomy (McMurray's type) with secondary osteoarthritis of the left hip and marked deformity of the proximal femur (case 1). Adapted from Vaishya et al. ${ }^{4)}$ with permission of CRC press.

(average, 64.3 years). The average time from the osteotomy to THR was 31.7 years (range, 29-36 years). Their brief clinical presentations are described below:

\section{Case 1}

A 68-year-old man presented with increasing pain, stiffness, and limping of the left leg lasting for the past 2 years. Hip pain had increased to such intensity that night sleep and activities of daily living were disturbed, and he was compelled to take regular pain killers. He had a history of a hip osteotomy performed 29 years ago for an ununited fracture of the femoral neck. His left lower limb was $4 \mathrm{~cm}$ shorter than the right one. Left hip movements were severely restricted and painful (Figs. 1 and 2).

\section{Case 2}

A 59-year-old male presented with pain and decreased movements of the right hip and shortening. He had sustained a fractured neck of the femur in a road traffic accident in 1982, which was treated by McMurray's osteotomy. He had experienced slowly increasing pain, stiffness, and shortening of the right limb since the surgery. For the last month, this pain had increased in severity, and there was difficulty in doing activities of daily living. The right hip movements were grossly restricted (flexion, $0^{\circ}-70^{\circ}$ and no rotations). There was a true shortening of $5 \mathrm{~cm}$ (Figs. 3 and 4).

\section{Case 3}

A 66-year-old male presented with right hip pain, stiffness, and shortening. There was a history of a road traffic accident in 1983, leading to a fracture of the neck of the femur. It was managed with McMurray's osteotomy, with fixation using a Wainright's plate. He was able to walk with short limb gait until 4 months ago when significant pain developed. The range of motion of the right hip was grossly restricted in all directions. There was a true shortening of $3 \mathrm{~cm}$ (Figs. 5 and 6).

\section{Surgical Procedure}

All these 3 cases underwent THR using a lateral modified Hardinge's approach in a lateral position. An adductor tenotomy was done as the first step. The hip could not be dislocated in 2 of the 3 cases and needed to be removed piecemeal. Significant peripheral and internal osteophytes (obscuring the true floor of the acetabulum) were present in all of the acetabulum. The internal osteophytes were reamed carefully to the floor of the acetabulum. After an incremental reaming of the acetabulum, a well-fitting acetabular cup was used ( 1 cemented and 2 uncemented). After the acetabular cup placement, the femur was prepared. The entry point of the femoral canal was located too medially and posteriorly. The entry was made with a drill bit and checked on an image intensifier. In 2 cases, the canal was narrow and was therefore reamed with flexible reamers over a guidewire. In all 3 cases, there was a bridge of bone encountered at the site of osteotomy, which needed to be drilled to open the femoral canal. In all cases, the femoral neck was found short, and the natural landmarks for neck osteotomy and evaluation of the version were absent. In case no. 1, the old osteotomy was not fully united and was found to be in a state of fibrous union and, 

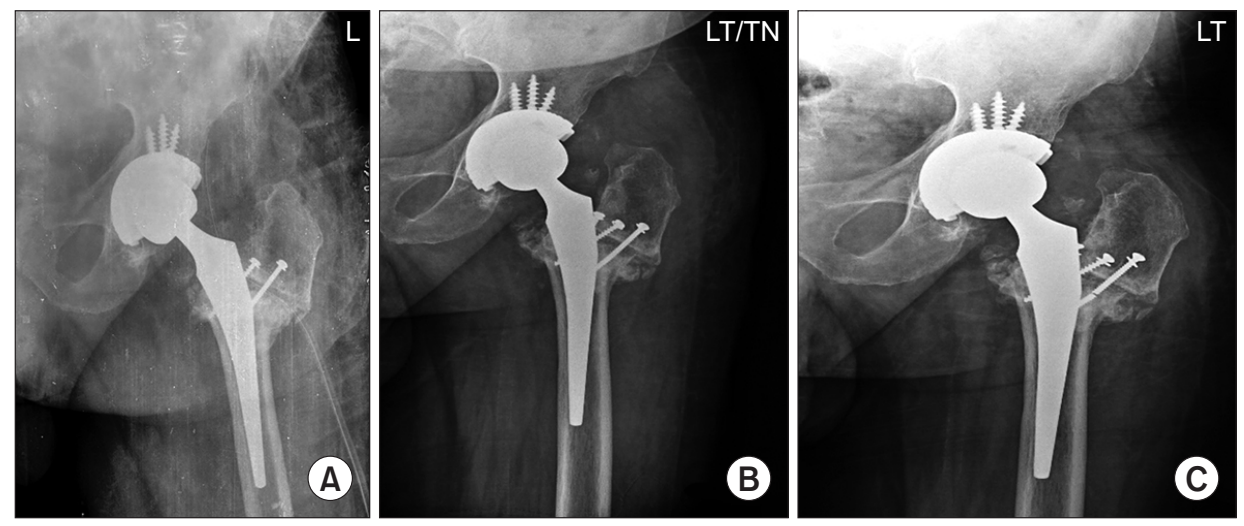

Fig. 2. Postoperative anteroposterior radiographs of the left hip showing acetabulum cup implantation at the true acetabulum level, with an excellent intramedullary filling of the prosthesis. (A) Immediately after surgery. (B) Four weeks after surgery. (C) Twelve weeks after surgery. Fixation of the intertrochanteric nonunion with 3 screws (case 1).

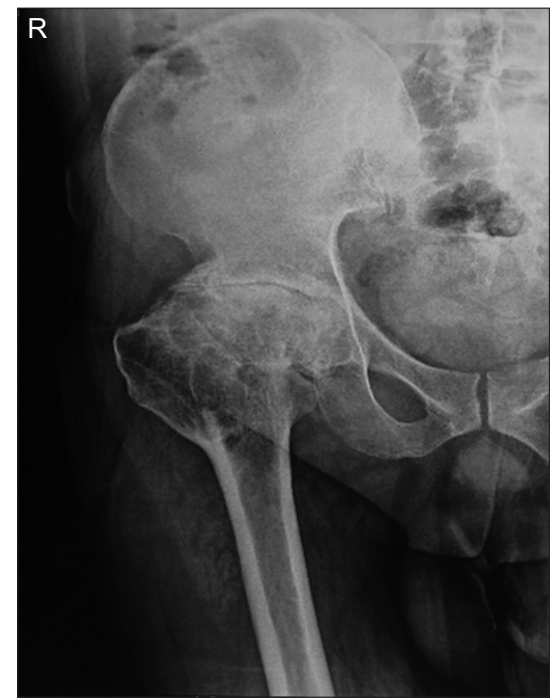

Fig. 3. Preoperative radiograph of the right hip joint showing decreased joint space, broadening of the greater trochanter and proximal femur, superior migration of proximal femur, no differentiation between femoral head and neck, and advanced osteoarthritic changes (case 2).

therefore it was fixed with 3 screws to stabilize the greater trochanter. The neck length and femoral offset were restored up to a reasonable tightness of the soft tissues. All the patients had a stable hip reduction after THR.

\section{RESULTS}

\section{Postoperative Care and Follow-up}

Postoperatively, the operated limb was kept in abduction in a brace. The patients were mobilized after 48 hours with a walking frame and partial weight-bearing. The weightbearing was gradually increased over 6 weeks. All the patients had pain-free hip, with minimal residual shortening (average, $1.2 \mathrm{~cm}$ ) at an average follow-up of 3.67 years (range, 1 to 6 years). The Harris hip score improved significantly postoperatively (Table 1 ) from an average of

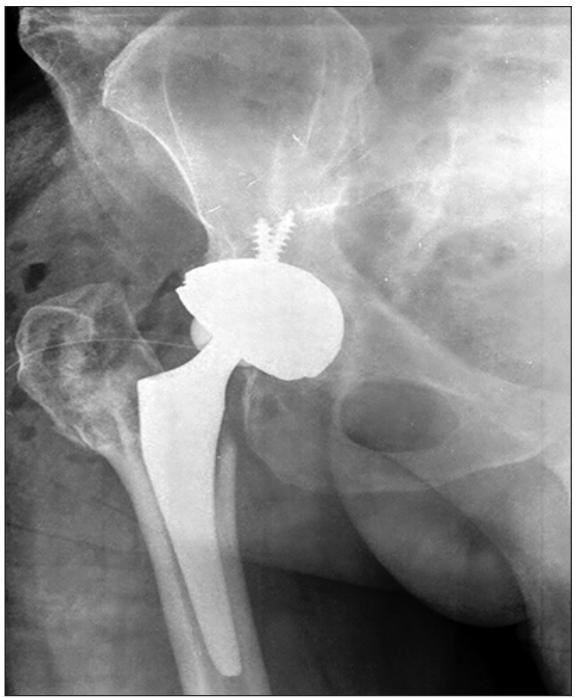

Fig. 4. Postoperative anteroposterior radiograph of the right hip showing acetabulum cup implantation at the true acetabulum level, with an excellent intramedullary filling of the prosthesis (case 2).
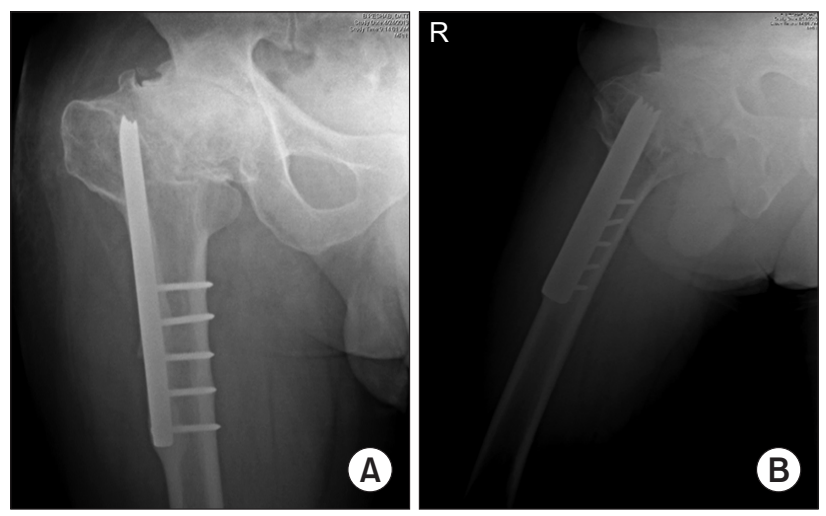

Fig. 5. Preoperative radiographs of the right hip joint: anteroposterior (A) and lateral (B) views, showing McMurray's osteotomy fixed with a Wainright's plate, irregularity of proximal femur, and advanced osteoarthritic changes (case 3). Adapted from Vaishya et al. ${ }^{4)}$ with permission of CRC press. 


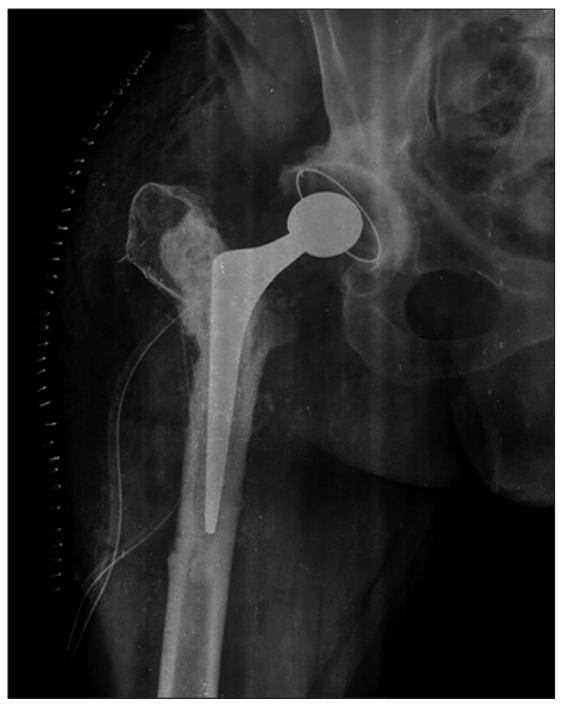

Fig. 6. Postoperative anteroposterior radiograph of the right hip, showing cemented femoral and acetabulum implants (case 3). Adapted from Vaishya et al. ${ }^{4)}$ with permission of CRC press.

61.7 (range, 59-65) to an average of 84.0 (range, 80-87), measured at the last follow-up. None of the hips showed any signs of loosening, instability, or abductor weakness.

\section{DISCUSSION}

In most of these cases, the osteotomy was done to buy time before a definitive replacement procedure can be employed. However, with the current availability of excellent fracture fixation devices such as cannulated cancellous screws, dynamic hip screws, and proximal femoral nails, fracture fixation for the femoral neck can be done satisfactorily, and the need for such an osteotomy is rare.

McMurray's osteotomy is a bifurcation osteotomy of the proximal femur where the shaft of the femur is directly transferred under the lower margin of the femoral head and acetabulum. In femoral neck fractures, it makes the fracture line more horizontal. It, therefore, converts the shearing forces to compressive forces, which helps in promoting the union of the fracture and provides an "armchair effect," which helps in painless weight-bearing even if the fracture fails to unite after this osteotomy. Robins ${ }^{5}$ in 1960 advised it for osteoarthritis of the hip and ununited fracture but not for avascular necrosis after fractured neck of the femur.

Phaltankar et al. ${ }^{6}$ ) noticed that since the osteotomy is done in the presence of preserved vascularity of the femoral head, collapse, and secondary osteoarthritis, the requirement of THR is uncommon. However, after a few decades of these surgical procedures, some surviving patients are expected to report secondary osteoarthritis of the hip, requiring THR. Since THR has been found to provide a marked improvement in pain and function in these cases, it remains a viable and useful option, although hip stiffness was found to be more than that in primary THR. ${ }^{3,7,8)}$ In a retrospective study of 74 THRs after hip osteotomy, ${ }^{9)}$ it was concluded that THR in these cases was technically more demanding but was not associated with any higher rate of complications. Nonunion of osteotomy is possible, especially if not fixed adequately by an implant and is often left with an asymptomatic fibrous nonunion.

THR is a challenging procedure after McMurray's osteotomy because of the abnormal anatomy of bones and soft tissues surrounding the hip joint.We believe that careful planning is necessary to do a THR in a previously osteotomized hip. ${ }^{4)}$ The use of 3-dimensional printing and virtual preoperative planning may be an immense help, and the use of this technology must be explored in such cases. ${ }^{10,11)}$ Specific technical considerations must be taken into account while performing THR, viz., (1) the location of the femoral entry point of the reamers, (2) the opening of the blocked medullary canal, (3) restoration of the hip center, (4) correction of limb length discrepancy, (5) fixation of a ununited trochanteric osteotomy, etc. The major problems encountered during THR and their solutions are discussed below.

\section{Bony Abnormalities and Difficulties}

(1) Dislocation of the femoral head is often difficult due to extensive soft-tissue contractures and extensive osteophytosis around the acetabulum. (2) The floor of the true acetabulum may be located deep and is obscured by the internal osteophytes, and it needs to be reamed carefully to reach the true acetabulum. (3) The femoral neck is shortened, and the landmarks for its osteotomy and interpreting the neck version are obscured and difficult to find. (4) The trochanter is laterally displaced to the femoral shaft, and hence, the entry point of the medullary canal of the femur is located much more medially and posteriorly than usual. Hence, a wrong entry into it may lead to iatrogenic fracture and wrong placement of the femoral stem. In some cases, reaming of the medullary canal with flexible reamers over a guidewire and under image intensifier is extremely helpful. In some cases, a trochanteric osteotomy may be needed to overcome the abovesaid problems. (5) Often there is a severe distortion of the neck and trochanteric anatomy and sometimes the formation of dense remodeled bone at the osteotomy site. This makes reaming of the femur and subsequent insertion of a prosthesis very difficult. DeCoster et $\mathrm{al}^{7)}$ advocated a re-osteotomy of the femur if there is 
marked distortion of the canal. We could, however, managed to do all our THR without any trochanteric osteotomy. (6) Lateralization of the trochanter after THR may cause abductor inefficiency as it may cause laxity of the abductor muscles and may lead to abductor weakness (although we did not encounter it in our 3 cases). Lateralization accompanied by distalization of the greater trochanter is known to increase the abductor lever arm, thereby giving advantage to the abductor muscle by increasing the resting length of the muscle fibres (Starling's law) and tension in the muscles. ${ }^{12,13)}$

\section{Soft-Tissue Abnormalities and Difficulties}

(1) Soft-tissue contractures and shortening of these structures attached to the upper end of the distal fragment lead to mild to moderate grades of flexion and adduction contracture. An adequate soft-tissue release is therefore required to create a head-stem offset as near to normal as possible. (2) Limb length discrepancy may not be corrected even after adequate surgical reduction due to soft-tissue contracture. An acute lengthening of more than $4 \mathrm{~cm}$ is not advisable to avoid an abnormal stretch of the sciatic nerve. ${ }^{14)}$ (3) Imbalanced muscle strength around the hip joint may cause excessive wearing of the articular surface and poor stability of the prosthesis, resulting in postoperative hip dislocation. ${ }^{3)}$ (4) Lateralization of the trochanter after THR may cause friction over the iliotibial band and possible pain.

\section{Choice of Hip Implants}

The choice of an implant for THR depends on the sur- geon's preference, experience, and the merit of the case. These implants could be cemented or uncemented. However, modular femoral components are useful ${ }^{9)}$ and should be necessarily available to address the distorted femoral anatomy after intertrochanteric osteotomy. The implants with proximal femoral sleeves may be helpful in hips with severe proximal femoral deficiency during THR.

McMurray's osteotomy was a popular salvage treatment option for fractured neck of the femur until 4 decades ago. Secondary hip osteoarthritis after this procedure requires THR at a later stage. THR after McMurray's osteotomy is often quite a challenging surgical procedure. These challenges are related to distorted bony anatomy, soft-tissue contractures, and the choice of implants. A detailed and careful preoperative planning, correct execution of the surgical techniques, and postoperative rehabilitation are the keys to the successful management of these cases.

\section{CONFLICT OF INTEREST}

No potential conflict of interest relevant to this article was reported.

\section{ACKNOWLEDGEMENTS}

We are extremely grateful to Dr. K.M. Iyer, the editor of the book entitled "Hip preservation techniques" for allowing us to use some of the figures from our own published article in his book.

\section{REFERENCES}

1. McMurray TP. Ununited fractures of the neck of the femur. J Bone Joint Surg. 1936;18(2):319.

2. Hermann OJ. The McMurray osteotomy for nonunited hip fractures. N Engl J Med. 1945;232(7):186-89.

3. Nagi ON, Dhillon MS. Total hip arthroplasty after McMurray's osteotomy. J Arthroplasty. 1991;6 Suppl:S17-22.

4. Vaishya R, Vaish A. McMurray's osteotomy: a forgotten procedure of the hip. In: Iyer KM, ed. Hip preservation techniques. Cleveland: CRC press; 2019. 125-29.

5. Robins RH. McMurray osteotomy. J Bone Joint Surg. 1960; 43:480-8.

6. Phaltankar PM, Bhavnani K, Kale S, Sejale S, Patel BR. Is McMurray's osteotomy obsolete? J Postgrad Med. 1995;41(4):102-3.
7. DeCoster TA, Incavo S, Frymoyer JW, Howe J. Hip arthroplasty after biplanar femoral osteotomy. J Arthroplasty. 1989;4(1):79-86.

8. Suzuki K, Kawachi S, Matsubara M, Morita S, Jinno T, Shinomiya K. Cementless total hip replacement after previous intertrochanteric valgus osteotomy for advanced osteoarthritis. J Bone Joint Surg Br. 2007;89(9):1155-7.

9. Boos N, Krushell R, Ganz R, Müller ME. Total hip arthroplasty after previous proximal femoral osteotomy. J Bone Joint Surg Br. 1997;79(2):247-53.

10. Mishra A, Verma T, Vaish A, Vaish R, Vaishya R, Maini L. Virtual preoperative planning and 3D printing are valuable for the management of complex orthopaedic trauma. Chin J Traumatol. 2019;22(6):350-5.

11. Vaishya R, Vijay V, Vaish A, Agarwal AK. Computed to- 
Vaishya et al. Total Hip Replacement after McMurray's Osteotomy

Clinics in Orthopedic Surgery • Vol. 12, No. 4, $2020 \bullet$ www.ecios.org

mography based 3D printed patient specific blocks for total knee replacement. J Clin Orthop Trauma. 2018;9(3):254-9.

12. Bjordal F, Bjorgul K. The role of femoral offset and abductor lever arm in total hip arthroplasty. J Orthop Traumatol. 2015;16(4):325-30.

13. Garcia-Rey E, Garcia-Cimbrelo E. Abductor biomechanics clinically impact the total hip arthroplasty dislocation rate: a prospective long-term study. J Arthroplasty. 2016;31(2):484-90.

14. Edwards BN, Tullos HS, Noble PC. Contributory factors and etiology of sciatic nerve palsy in total hip arthroplasty. Clin Orthop Relat Res. 1987;(218):136-41. 